\title{
Real-Life ILUVIEN (Fluocinolone Acetonide) Case Study: Rapid Drying of the Macula and Improved Vision within 2 Years after Therapy Initiation
}

\author{
Hibba Quhill Fahd Quhill \\ Royal Hallamshire Hospital, Sheffield, UK
}

\section{Keywords}

ILUVIEN · Diabetic macular oedema - Visual acuity $\cdot$ Central foveal thickness

\begin{abstract}
Importance: A case showing sustained structural and functional responses 2 years after a single treatment with ILUVIEN $(0.2 \mu \mathrm{g} /$ day fluocinolone acetonide, FAc) despite suboptimal responses to ranibizumab. Observations: A 68-year-old female patient with diabetic macular oedema (DME) from type 2 diabetes mellitus was first diagnosed in October 2010 and had a baseline visual acuity (VA) of 46 Early Treatment Diabetic Retinopathy Study (ETDRS) letters in the left eye. Central foveal thickness (CFT) was 712 microns. The patient was treated with 11 intravitreal injections of ranibizumab (5 in combination with a small-interfering RNA agent), and by March 2014, VA and CFT were largely unchanged (55 ETDRS letters and 774 microns). The patient was treated with ILUVIEN as she had a pseudophakic lens and a clearly suboptimal response to the prior therapy with ranibizumab. An implant releasing FAc at a dosage of $0.2 \mu \mathrm{g} /$ day was administered in March 2014, and the optical coherence tomography indicated that the macula was dry after 7 days (CFT was below 300 microns). This was
\end{abstract}




\section{Case Reports in Ophthalmology}

Case Rep Ophthalmol 2016;7:301-307

DOI: $10.1159 / 000452883$

(c) 2016 The Author(s). Published by S. Karger AG, Basel www.karger.com/cop

Quhill and Quhill: Real-Life ILUVIEN (Fluocinolone Acetonide) Case Study: Rapid Drying of the Macula and Improved Vision within 2 Years after Therapy Initiation

sustained at 6,12, and 24 months after the treatment. VA improved by 5 letters within 7 days and by 15 letters within 14 days, and this was maintained after 24 months. Throughout the duration of this study, the intraocular pressure was $\leq 22 \mathrm{~mm} \mathrm{Hg}$, and no glaucoma medication was administered. Conclusions and Relevance: In real-life UK practice, this DME patient showed a suboptimal response to multiple intravitreal injections of ranibizumab. When subsequently treated with a single injection of ILUVIEN, there were large and rapid improvements in VA and CFT that were maintained for the following 2 years.

(C) 2016 The Author(s)

Published by S. Karger AG, Basel

\section{Background}

Worldwide diabetic macular edema (DME) is reported to have a prevalence of $6.8 \%$ and results in vision loss [1]. DME management can be difficult, with only around $15 \%$ of the patients achieving significant vision recovery with laser, the current standard of care [2]. A number of pharmacotherapies are now licensed for the treatment of DME in Europe, including anti-vascular endothelial growth factor agents and corticosteroid therapies [3], which are used to target vascular endothelial growth pathways and inflammatory pathways, respectively.

In diabetes, there is increased expression of leukocyte adhesion molecules on the endothelial cell walls. Leukocytes release free radicals and enzymes that cause direct damage to endothelial cells, increasing blood retinal barrier leakage. They also release cytokines, including vascular endothelial growth factor, tumor necrosis factor- $\alpha$, and interleukin- 6 , which act through various signaling pathways to increase vascular permeability [4].

Corticosteroids are known anti-inflammatory and angiostatic agents. Inhibiting the release of cytokines with a corticosteroid - such as dexamethasone, triamcinolone or fluocinolone - has been shown to reduce DME and rehabilitate vision in several pivotal clinical studies [3]. ILUVIEN contains the corticosteroid fluocinolone acetonide (FAc) and uses microdosing ${ }^{\mathrm{TM}}$ technology to release FAc at a daily rate of $0.2 \mu \mathrm{g}$ for up to 3 years [5]. This differs significantly from both the dexamethasone delivery system and that of triamcinolone, which are reported to have a duration of action of only up to 3 and 4 months, respectively [6]. The effectiveness of ILUVIEN was demonstrated in the FAME trials (NCT00344968) in which patients with DME who had previously shown an insufficient response to laser were treated with either a $0.2 \mu \mathrm{g} /$ day (ILUVIEN) or $0.5 \mu \mathrm{g} /$ day FAc implant and were compared against a sham-control treated population. Both FAME trials independently met their primary endpoint and showed that significantly more patients with chronic DME treated with the 0.2 $\mu \mathrm{g} /$ day FAc implant experienced a $\geq 15$-letter improvement in visual acuity (VA) at month 24 than sham-control patients (pooled data; 34.4 vs. $13.4 \% ; p<0.001$ ) and that this benefit was sustained to month 36 . Functional improvements were accompanied by rapid and sustained improvements in central foveal thickness (CFT) [5].

In Europe, ILUVIEN was first licensed in 2012. ILUVIEN is indicated for the treatment of vision impairment associated with chronic diabetic macular oedema considered insufficiently responsive to available therapies. Since then, its usage in real-life clinical practice has steadily been increasing. Miss Clare Bailey presented the real world outcomes from a UK 
audit of patients treated with ILUVIEN at the annual meeting of the Royal College of Ophthalmologists in Birmingham, UK, between June 24 and 26, 2016. This unpublished interim analysis showed that the majority of treated eyes ( $\geq 69.4 \%$ of 290 eyes) maintained or improved VA. To date, however, relatively limited data with a longer-term follow-up of the functional and structural responses following treatment with ILUVIEN have been reported. The case described herein provides data for both VA and CFT over a 24-month follow-up period.

\section{Case Presentation}

A 68-year-old Caucasian female with type 2 diabetes mellitus had diffuse DME diagnosed in her left eye in October 2010. The treatment history is summarised in Table 1 and was previously reported when only 6 months of follow-up were available. At diagnosis, VA was 46 Early Treatment Diabetic Retinopathy Study (ETDRS) letters, converted from Snellen VA using the equation $85+50 \times \log$ (Snellen fraction), CFT was 712 microns, and intraocular pressure (IOP) was $\leq 22 \mathrm{~mm} \mathrm{Hg}$.

The patient had phacoemulsification plus intraocular lens insertion in the left eye in February 2012. Intravitreal triamcinolone acetonide was also administered to treat the persistent DME postoperatively. At the first postoperative visit, VA was 70 ETDRS letters, CFT was 278 microns, and IOP was $20 \mathrm{~mm} \mathrm{Hg}$. Over the next 5 months, VA (50 ETDRS letters) and CFT (805 microns) progressively worsened, and the patient was admitted into the Matisse trial in September 2012 to test the effects of ranibizumab plus a small-interfering RNA agent.

Between October 2012 and March 2014, the patient received 5 injections of ranibizumab plus the small-interfering RNA agent and then subsequently listed for 2 further courses of 3 intravitreal injections of ranibizumab. By the end of this stage of treatment, by 1 month after the final injection of ranibizumab, the DME had recurred, VA was 55 ETDRS letters, CFT was 774 microns, and IOP was $17 \mathrm{~mm} \mathrm{Hg}$.

The patient's DME was now chronic (over 18 months of duration), relapsing, and her CRT had fluctuated wildly through the different treatment phases, which is believed to have a deleterious effect on the function of the retina and, more specifically, on the visual function due to the presence of submacular fluid [7]. It was at this stage that the patient was treated with ILUVIEN according to NICE TA301 (please see http://www.nice.org.uk/ guidance/ta301/chapter/1-Guidance). Figure 1 shows the response of VA and CFT after a single ILUVIEN implant without any further treatment to this eye over the next 2 years. Within 7 days, VA had increased to 61 ETDRS letters and CFT had decreased to 267 microns. Within 2 weeks, VA had improved further to 70 ETDRS letters, which is the legal requirement to hold a driving license in the UK. These early improvements were then largely maintained throughout the next 24 months without further intervention, as shown in Figure 1. Figure 2 shows optical coherence tomography scans before and after ILUVIEN implantation, illustrating the structural improvement that occurred alongside the functional improvement in vision. Over the course of the 2-year period, IOP remained below $21 \mathrm{~mm} \mathrm{Hg}$, and no IOPlowering medication was required. 


\section{Case Reports in Ophthalmology}

\begin{tabular}{l|l}
\hline Case Rep Ophthalmol 2016;7:301-307 \\
\hline DOI: $10.1159 / 000452883$ & $\begin{array}{l}\text { (c) 2016 The Author(s). Published by S. Karger AG, Basel } \\
\text { www.karger.com/cop }\end{array}$ \\
\hline
\end{tabular}

Quhill and Quhill: Real-Life ILUVIEN (Fluocinolone Acetonide) Case Study: Rapid Drying of the Macula and Improved Vision within 2 Years after Therapy Initiation

\section{Conclusion}

This is the first case that the authors are aware of, which shows that a single injection of the $0.2 \mu \mathrm{g} /$ day FAc implant leads to rapid improvements (within 7 days) in VA and CFT that are maintained over 2 years of follow-up. This was despite 11 previous injections of ranibizumab, which failed to control the DME prior to treatment with ILUVIEN. The functional and structural responses presented herein are consistent with those reported in the FAME trials, with rapid and marked responses observed early and being sustained in the long term. This patient will continue to be monitored to see if the responses reported in controlled clinical trials are replicated with a single injection in real-life UK practice over a 36month period.

\section{Acknowledgements}

The publication of this article was supported by Alimera Sciences Ltd. The authors would like to thank Mr. Acharya and Mr. Brand for their help with the management of the patient.

\section{Statement of Ethics}

This article does not contain any new studies with human or animal subjects performed by any of the authors.

\section{Disclosure Statement}

Dr. H. Quhill and Mr. F. Quhill have no conflicts of interest relating to this publication. Mr. F. Quhill has attended advisory boards and speaker engagements and has been remunerated for these by Alimera Sciences.

\section{References}

1 Yau JW, Rogers SL, Kawasaki R, et al: Global prevalence and major risk factors of diabetic retinopathy. Diabetes Care 2012;35:556-564.

2 Boyer DS, Hopkins JJ, Sorof J, Ehrlich JS: Anti-vascular endothelial growth factor therapy for diabetic macular edema. Ther Adv Endocrinol Metab 2013;4:151-169.

-3 Singer MA, Kermany DS, Waters J, Jansen ME, Tyler L: Diabetic macular edema: it is more than just VEGF. F1000Res pii: F1000Faculty Rev-1019.

4 Wenick A, Bressler N: Diabetic macular edema: current and emerging therapies. Middle East Afr J Ophthalmol 2012;19:4-12.

5 ILUVIEN Summary of Product Characteristics. https://www.medicines.org.uk/emc/medicine/27636 (accessed June 22, 2016). 
Quhill and Quhill: Real-Life ILUVIEN (Fluocinolone Acetonide) Case Study: Rapid Drying of the Macula and Improved Vision within 2 Years after Therapy Initiation

6 Stewart MW, Flynn HW Jr, Schwartz SG, Scott IU: Extended duration strategies for the pharmacologic treatment of diabetic retinopathy: current status and future prospects. Expert Opin Drug Deliv 2016, Epub ahead of print.

7 Sophie R, Lu N, Campochiaro PA: Predictors of functional and anatomic outcomes in patients with diabetic macular edema treated with ranibizumab. Ophthalmology 2015;122:1395-1401.
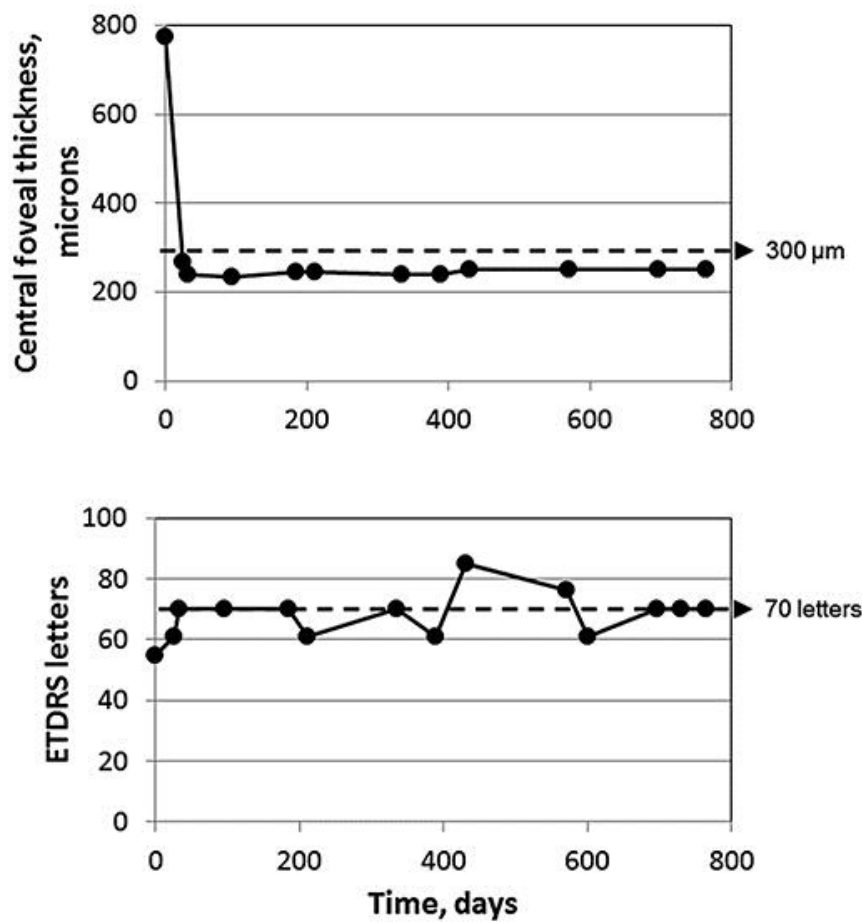

Fig. 1. The change in central foveal thickness (top panel) and visual acuity (bottom panel) following intravitreal injection of ILUVIEN. 


\section{Case Reports in Ophthalmology}

Case Rep Ophthalmol 2016;7:301-307

(C) 2016 The Author(s). Published by S. Karger AG, Basel www.karger.com/cop

Quhill and Quhill: Real-Life ILUVIEN (Fluocinolone Acetonide) Case Study: Rapid Drying of the Macula and Improved Vision within 2 Years after Therapy Initiation
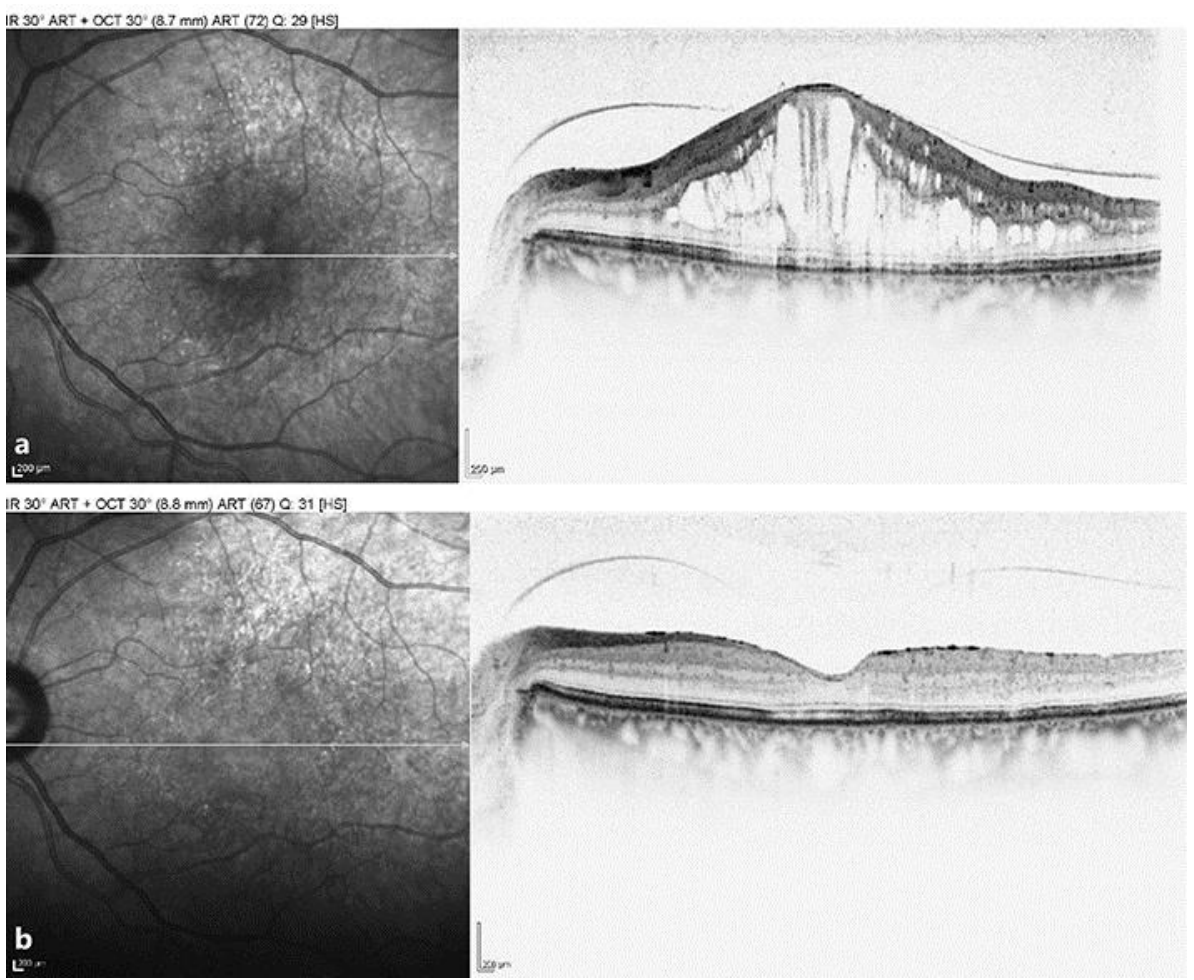

Fig. 2. Optical coherence tomography scan showing the foveal thickness prior to (a; March 2011) and 2 years after intravitreal ILUVIEN (b; April 2016) in the left eye. 
Table 1. Treatment history of the left eye

\begin{tabular}{|c|c|c|c|c|c|}
\hline Date & $\begin{array}{l}\text { Number of days } \\
\text { between visits }\end{array}$ & Description & VA & $\begin{array}{l}\text { ETDRS } \\
\text { letters }\end{array}$ & $\begin{array}{l}\mathrm{CFT} \text {, } \\
\text { microns }\end{array}$ \\
\hline $13 / 07 / 2009$ & 224 & Proliferative retinopathy diagnosed & NN & NN & $\mathrm{NN}$ \\
\hline $14 / 08 / 2009$ & 32 & Panretinal laser photocoagulation & $6 / 6$ & 85 & $\mathrm{NN}$ \\
\hline $21 / 10 / 2009$ & 68 & Quiecscent laser-treated retinopathy & $6 / 6$ & 85 & NN \\
\hline $20 / 10 / 2010$ & 364 & Diffuse DME diagnosed & $6 / 36$ & 46 & 712 \\
\hline $19 / 11 / 2010$ & 30 & IVTA injection & NN & NN & NN \\
\hline $14 / 12 / 2010$ & 25 & Underwent macular grid & $6 / 18$ & 61 & 304 \\
\hline $25 / 01 / 2011$ & 42 & Visit & $6 / 18$ & 61 & 283 \\
\hline $02 / 03 / 2011$ & 36 & Visit & $6 / 12$ & 70 & 279 \\
\hline $18 / 01 / 2012$ & 322 & Dense cataract & $6 / 36$ & 46 & 612 \\
\hline $02 / 02 / 2012$ & 15 & $\begin{array}{l}\text { Phacoemulsification; +IOL; IVTA to treat } \\
\text { cataract and recurrent DME }\end{array}$ & NN & NN & $\mathrm{NN}$ \\
\hline $16 / 04 / 2012$ & 74 & Visit & $6 / 12$ & 70 & 278 \\
\hline $31 / 08 / 2012$ & 137 & Visit & $6 / 36$ & 46 & 769 \\
\hline $24 / 09 / 2012$ & 24 & $\begin{array}{l}\text { Visit; admitted into the Matisse trial } \\
\text { (ranibizumab + siRNA agent) }\end{array}$ & $6 / 30$ & 50 & 805 \\
\hline $08 / 10 / 2012$ & 14 & 1st study injection & $\mathrm{NN}$ & NN & NN \\
\hline $12 / 11 / 2012$ & 35 & 2nd study injection & $6 / 15$ & 65 & 352 \\
\hline $10 / 12 / 2012$ & 28 & 3rd study injection & $6 / 12$ & 70 & 279 \\
\hline $07 / 01 / 2013$ & 28 & 4th study injection & $6 / 9$ & 76 & 271 \\
\hline $04 / 02 / 2013$ & 28 & 5th study injection & $6 / 9$ & 76 & 304 \\
\hline $04 / 03 / 2013$ & 28 & Visit & $6 / 9$ & 76 & 332 \\
\hline $08 / 04 / 2013$ & 35 & $\begin{array}{l}\text { Patient exits study listed for ranibizumab } \\
\text { injection due to residual and progressive DME }\end{array}$ & $6 / 12$ & 70 & 577 \\
\hline $06 / 06 / 2013$ & 59 & Ranibizumab injection & $\mathrm{NN}$ & NN & $\mathrm{NN}$ \\
\hline $09 / 07 / 2013$ & 33 & Ranibizumab injection & NN & NN & NN \\
\hline $23 / 08 / 2013$ & 45 & Ranibizumab injection & NN & NN & NN \\
\hline $07 / 09 / 2013$ & 15 & Visit & $6 / 36$ & 46 & 451 \\
\hline $17 / 10 / 2013$ & 40 & Ranibizumab injection & NN & NN & NN \\
\hline $21 / 11 / 2013$ & 35 & Ranibizumab injection & $\mathrm{NN}$ & NN & $\mathrm{NN}$ \\
\hline $10 / 01 / 2014$ & 50 & Ranibizumab injection & NN & NN & NN \\
\hline $03 / 03 / 2014$ & 52 & Visit & $6 / 24$ & 55 & 774 \\
\hline $21 / 03 / 2014$ & 18 & ILUVIEN injection & NN & $\mathrm{NN}$ & $\mathrm{NN}$ \\
\hline $28 / 03 / 2014$ & 7 & Visit & $6 / 18$ & 61 & 267 \\
\hline $04 / 04 / 2014$ & 7 & Visit & $6 / 12$ & 70 & 241 \\
\hline $06 / 06 / 2014$ & 63 & Visit & $6 / 12$ & 70 & 234 \\
\hline $04 / 09 / 2014$ & 90 & Visit & $6 / 12$ & 70 & 245 \\
\hline $30 / 09 / 2014$ & 26 & Visit & $6 / 18$ & 61 & 245 \\
\hline $01 / 02 / 2015$ & 124 & Visit & $6 / 12$ & 70 & 239 \\
\hline $28 / 03 / 2015$ & 55 & Visit & $6 / 18$ & 61 & 240 \\
\hline $08 / 05 / 2015$ & 41 & Visit & $6 / 6$ & 85 & 251 \\
\hline $25 / 09 / 2015$ & 140 & Visit & $6 / 9$ & 76 & 252 \\
\hline $24 / 10 / 2015$ & 29 & Visit & $6 / 18$ & 61 & NN \\
\hline $28 / 01 / 2016$ & 96 & Visit & $6 / 12$ & 70 & 250 \\
\hline $02 / 03 / 2016$ & 34 & Visit & $6 / 12$ & 70 & NN \\
\hline $06 / 04 / 2016$ & 94 & Visit & $6 / 12$ & 70 & 250 \\
\hline
\end{tabular}

VA, visual acuity; ETDRS, Early Treatment Diabetic Retinopathy Study; CFT, central foveal thickness; IVTA, intravitreal triamcinolone acetonide; NN, no numbers; IOL, intraocular lens; siRNA, small-interfering RNA; DME, diabetic macular oedema. 